\title{
Usar tecnologias digitais nas aulas remotas durante a pandemia da COVID-I 9? Sim, mas quais e como usar?
}

\author{
To use digital technologies in remote lessons during the COVID-I 9 \\ pandemic? Yes, but which and how to use? \\ ¿Utiliza tecnologías digitales en lecciones remotas durante la \\ pandemia COVID-I9? Sí, ¿Pero qué y cómo utilizar?
}

\author{
Márcia Gorett Ribeiro Grossi ${ }^{1}$
}

http://orcid.org/0000-0002-3550-6680

Resumo: $\mathrm{O}$ objetivo deste artigo foi analisar o potencial educativo das tecnologias digitais utilizadas no processo de ensino e aprendizagem das aulas remotas ofertadas durante a suspensão das aulas devido à pandemia da COVID-19. Para tal, realizou-se uma pesquisa qualitativa e descritiva. Em relação aos procedimentos técnicos, optou-se pela pesquisa bibliográfica. Os resultados permitem concluir que o potencial educativo dessas tecnologias reside no fato de que elas são capazes de transformar o ensino e têm um lugar na construção do conhecimento, exercendo um papel importante no novo contexto educacional, cuja sala de aula passou a ser virtual. A pesquisa apresentou as principais tecnologias digitais que podem ser usadas nas aulas remotas e suas aplicações em estratégias pedagógicas, apontando suas vantagens. Por fim, destaca-se a necessidade das escolas e dos professores refletirem sobre o uso das tecnologias digitais na educação, pois elas vieram para ficar, sendo fundamental a apropriação tecnológica nas práticas docentes.

Palavras-chave: Ensino remoto. Tecnologias educacionais. Pandemia da COVID-19.

\begin{abstract}
The objective of this article was to analyze the educational potential of digital technologies used in the teaching and learning process of remote classes offered during the suspension of classes due to the COVID19 pandemic. To this end, it was carried out a qualitative and descriptive research. Regarding technical procedures, bibliographic research was chosen. The results allow to conclude that the educational potential of these technologies lies in the fact that they are capable of transforming teaching and have a place in the construction of knowledge, playing an important role in the new educational context, whose classroom has become virtual way. The research presented the main digital technologies that can be used in remote classes and its applications in pedagogical strategies, pointing out their advantages. Finally, the need of schools and teachers to reflect on the use of digital technologies in education is highlighted, because they are here to stay, being fundamental the technological appropriation in teaching practices.
\end{abstract}

Keywords: Remote education. Educational technologies. COVID-19 pandemic.

\footnotetext{
' Doutora em Ciência da Informação pela Universidade Federal de Minas Gerais (UFMG). Professora Titular do Departamento de Educação do Centro Federal de Educação Tecnológica de Minas Gerais (CEFET-MG). Líder do Grupo de Pesquisa AVACEFETMG. E-mail: marciagrossi@terra.com.br
} 
Resumen: El objetivo de este artículo fue analizar el potencial educativo de las tecnologías digitales utilizadas en el proceso de enseñanza y aprendizaje de clases remotas ofrecidas durante la suspensión de clases debido a la pandemia de COVID-19. Para ello, se realizó una investigación cualitativa y descriptiva. En cuanto a los procedimientos técnicos, se eligió la investigación bibliográfica. Los resultados permiten concluir que el potencial educativo de estas tecnologías radica en el hecho de que son capaces de transformar la enseñanza y tienen un lugar en la construcción del conocimiento, desempeñando un papel importante en el nuevo contexto educativo, cuyo aula se ha convertido en una forma virtual. La investigación presentó las principales tecnologías digitales que pueden utilizarse en clases remotas y sus aplicaciones en estrategias pedagógicas, señalando sus ventajas. Finalmente, se destaca la necesidad de que las escuelas y los docentes reflexionen sobre el uso de las tecnologías digitales en la educación, porque están aquí para quedarse, siendo fundamental la apropiación tecnológica en las prácticas docentes.

Palabras-clave: Educación remota. Tecnologías educativas. Pandemia de COVID-I9.

No início de 2020, o mundo foi surpreendido com um vírus que em poucos meses se tornou uma pandemia (COVID-19), o novo coronavírus. Seu combate tem sido a prioridade e o maior desafio da humanidade nos últimos tempos. Assim, a forma de viver do planeta se transformou repentinamente, em todos os seus segmentos. Dentre esses, destaca-se neste artigo a educação.

Para conter o contágio e proliferação da doença, o isolamento social se fez necessário e as escolas foram fechadas e tiveram suas aulas suspensas. Como consequência, mais de I,5 bilhão de alunos de 165 países foram afetados pelo fechamento de escolas, o que equivale a 87\% da população estudantil, conforme dados da Organização das Nações Unidas para a Educação, Ciência e Cultura (UNESCO).

Frente a essa situação, o governo brasileiro, em 17 de março de 2020, assinou a Portaria $n^{\circ} 343$, a qual dispõe sobre a substituição das aulas presenciais por aulas em meios digitais enquanto durar a situação de pandemia da COVID-19. Essa portaria foi ajustada e substituída pela Portaria n³45, em 19 de março de 2020.

Portanto, amparados pelas legislações e com o objetivo de minimizar o prejuízo no aprendizado dos alunos, as escolas começaram a ofertar suas aulas a distância via internet. Porém, nem todas estavam preparadas para a transição de um modelo de ensino para outro, principalmente porque o novo modelo é totalmente dependente das Tecnologias Digitais de Informação e Comunicação (TDIC). Vale dizer, que as TDIC já estavam sendo incorporadas aos poucos nas rotinas das salas de aula, por exemplo, através da adoção das metodologias ativas enquanto estratégias pedagógicas, por meio dos modelos de ensino híbrido e da sala de aula invertida.

O ensino híbrido, de acordo com Martins (2016, p. 68) faz uma combinação entre "o modelo tradicional, no sentido de envolver a aprendizagem em sala de aula, como vem sendo 
realizado há tempos, e o modelo online, que utiliza as tecnologias digitais para promover o ensino". Para a autora, no ensino híbrido, professores e alunos ensinam e aprendem em tempos e locais variados.

Já a sala de aula invertida é um modelo no qual a teoria é estudada em casa no formato online e, na sala de aula presencial são desenvolvidos debates e atividades sobre o conteúdo estudado em casa. "O que era feito na sala de aula (explicação do conteúdo) é agora feito em casa e, o que era feito em casa (aplicação, atividades sobre o conteúdo) é agora feito na sala de aula" (MARTINS, 2016, p. 77).

Assim, a educação estava ficando mais flexível, híbrida, digital, ativa e diversificada (MORAN, 20I7). Contudo, a pandemia da COVID-19, atropelou esse processo e acelerou o futuro da educação. Fez com que as escolas pulassem etapas e a tecnologia digital se tornasse a ponte de acesso entre professores e alunos.

Nessa perspectiva, surgiu a questão: como as tecnologias digitais podem ser inseridas nas práticas pedagógicas das aulas ofertadas remotamente via internet? Para respondê-la, foi realizado um estudo com o objetivo de analisar o potencial educativo das tecnologias digitais utilizadas no processo de ensino e aprendizagem das aulas remotas ofertadas durante a suspensão das aulas devido à pandemia da COVID-19. Para tal, realizou-se em 2020, uma pesquisa de abordagem qualitativa. De acordo com o objetivo traçado, o tipo de pesquisa foi a descritiva e, em relação aos procedimentos técnicos, escolheu-se a pesquisa bibliográfica.

\section{Ensino remoto e suas aproximações}

Quando as aulas presenciais foram substituídas pelas aulas online, vários termos começaram a fazer parte da esfera educacional, tais como: ensino remoto, educação a distância $(E a D)$, ensino híbrido, homeschooling, entre outros. E, o que se viu, foi uma confusão entre eles. Entretanto, o ensino que vem sendo adotado em caráter emergencial, é o remoto. No Quadro I estão apresentadas as diferenças entre os referidos termos.

Olhar de professor, Ponta Grossa, v. 24, p. I-12, e-15879.059, 202 I. 
Usar tecnologias digitais nas aulas remotas durante a pandemia da COVID-19? Sim, mas quais e como usar?

Quadro I - Síntese comparativa dos segmentos educacionais e estratégias pedagógicas.

\begin{tabular}{|c|c|c|c|c|c|c|}
\hline \multicolumn{7}{|c|}{ Segmentos educacionais / estratégias pedagógicas } \\
\hline & $\begin{array}{l}\mathrm{EaD}(100 \% \\
\text { online })\end{array}$ & $\begin{array}{c}\text { EaD } \\
\text { Semipresenci } \\
\text { al } \\
\text { com até } 20 \% \\
\text { da carga } \\
\text { horária total } \\
\text { a distância }\end{array}$ & $\begin{array}{c}\text { Ensino } \\
\text { Híbrido } \\
\text { (com carga } \\
\text { horária } \\
\text { inferior à } \\
\text { exigida por lei } \\
\text { para a EaD } \\
\text { semipresencial) }\end{array}$ & Ensino Remoto & $\begin{array}{l}\text { Ensino domiciliar } \\
\text { ou Homeschooling }\end{array}$ & $\begin{array}{l}\text { Sala de } \\
\text { aula } \\
\text { invertida }\end{array}$ \\
\hline $\begin{array}{l}\text { É considerada } \\
\text { uma } \\
\text { modalidade de } \\
\text { educação, de } \\
\text { acordo com o } \\
\text { MEC? }\end{array}$ & $\begin{array}{l}\text { Sim, por } \\
\text { meio da } \\
\text { LDB n } \\
9.394 / 96, \\
\text { Art. } 80\end{array}$ & $\begin{array}{l}\text { Sim, por } \\
\text { meio do } \\
\text { Decreto } n^{\circ} \\
5.622 / 05\end{array}$ & Não & Não & $\begin{array}{l}\text { Não, mas existe } \\
\text { um Projeto de Lei } \\
\mathrm{n}^{\circ} 3.291 / 15 \text {, para } \\
\text { que se torne uma } \\
\text { modalidade de } \\
\text { educação. }\end{array}$ & Não \\
\hline $\begin{array}{l}\text { É considerada } \\
\text { uma estratégia } \\
\text { / abordagem } \\
\text { pedagógica? }\end{array}$ & Não & Não & Sim & $\begin{array}{l}\text { Sim, mas de } \\
\text { caráter } \\
\text { emergencial } \\
\text { aprovada pelo } \\
\text { MEC, Portaria } \\
n^{\circ} 343 / 20, \\
\text { devido à } \\
\text { pandemia da } \\
\text { COVID-19 }\end{array}$ & Não & Sim \\
\hline $\begin{array}{l}\text { É uma } \\
\text { metodologia } \\
\text { ativa? }\end{array}$ & Não & Não & Sim & Não & Não & Sim \\
\hline $\begin{array}{l}\text { Quem faz } \\
\text { parte do } \\
\text { processo de } \\
\text { ensino e } \\
\text { aprendizagem? }\end{array}$ & $\begin{array}{l}\text { Alunos, } \\
\text { professores } \\
\text { e tutores } \\
\text { a distância }\end{array}$ & $\begin{array}{l}\text { Alunos, } \\
\text { professores, } \\
\text { tutores } \\
\text { a distância } \\
\text { e presenciais }\end{array}$ & $\begin{array}{l}\text { Alunos e } \\
\text { professores }\end{array}$ & $\begin{array}{l}\text { Alunos } \\
\text { e professores. } \\
\text { No caso das } \\
\text { etapas do } \\
\text { ensino } \\
\text { fundamental e } \\
\text { educação } \\
\text { infantil, os pais } \\
\text { têm participado } \\
\text { também. }\end{array}$ & $\begin{array}{l}\text { Alunos, pais e/ou } \\
\text { professores } \\
\text { particulares }\end{array}$ & $\begin{array}{l}\text { Alunos } \\
\text { e } \\
\text { professore } \\
\text { s }\end{array}$ \\
\hline $\begin{array}{l}\text { Existe o apoio } \\
\text { de tutores, } \\
\text { para tirar } \\
\text { dúvidas dos } \\
\text { alunos por } \\
\text { meio de chat, } \\
\text { e-mail, } \\
\text { Whatsapp e } \\
\text { fóruns? }\end{array}$ & Sim & Sim & Não & Não & Não & Não \\
\hline $\begin{array}{l}\text { Professores e } \\
\text { alunos } \\
\text { ensinam e } \\
\text { aprendem em } \\
\text { tempos e } \\
\text { locais } \\
\text { variados? }\end{array}$ & Sim & Em parte & Em parte & Sim & Não & Em parte \\
\hline
\end{tabular}

Olhar de professor, Ponta Grossa, v. 24, p. I-12, e-15879.059, 202 I.

Disponível em <https://revistas2.uepg.br/index.php/olhardeprofessor> 


\begin{tabular}{|c|c|c|c|c|c|c|}
\hline $\begin{array}{l}100 \% \text { das } \\
\text { aulas são } \\
\text { baseadas nos } \\
\text { Ambientes } \\
\text { Virtuais de } \\
\text { Aprendizagem? }\end{array}$ & Sim & Não & Não & $\begin{array}{l}\text { Não, também } \\
\text { pode usar } \\
\text { material } \\
\text { impresso }\end{array}$ & Não & Não \\
\hline $\begin{array}{l}\text { Precisa de } \\
\text { internet? }\end{array}$ & Sempre & As vezes & Ás vezes & $\begin{array}{l}\text { Sim, quando } \\
\text { não se usa } \\
\text { material } \\
\text { impresso }\end{array}$ & $\begin{array}{l}\text { Não } \\
\text { necessariamente }\end{array}$ & $\begin{array}{l}\text { Não } \\
\text { necessaria } \\
\text { mente }\end{array}$ \\
\hline $\begin{array}{l}\text { Mescla } \\
\text { práticas } \\
\text { pedagógicas } \\
\text { do ensino } \\
\text { presencial e } \\
\text { do ensino a } \\
\text { distância? }\end{array}$ & Não & Às vezes & Sim & Não & É possível & É possível \\
\hline $\begin{array}{l}\text { Os horários } \\
\text { para assistir às } \\
\text { aulas online } \\
\text { são flexíveis? }\end{array}$ & Sim & Sim & Pode ser & Pode ser & Não & Não \\
\hline $\begin{array}{l}\text { As avaliações } \\
\text { são feitas nos } \\
\text { encontros } \\
\text { presenciais? }\end{array}$ & Não & $\begin{array}{l}\text { Não } \\
\text { necessariame } \\
\text { nte }\end{array}$ & Pode ser & $\begin{array}{l}\text { Não } \\
\text { necessariament } \\
\text { e }\end{array}$ & Não se aplica & Sim \\
\hline $\begin{array}{l}\text { Indicado para } \\
\text { qualquer } \\
\text { idade? }\end{array}$ & Não & Não & Sim & Não & Sim & Sim \\
\hline
\end{tabular}

Fonte: Adaptado de Grossi, 2020.

Frente aos dados do Quadro I, percebe-se que o ensino remoto, que segue os princípios da educação presencial (COSTA, 2020), tem aproximações com a EaD, no sentido de que possui algumas de suas características, como professores e alunos estarem distantes fisicamente e interagirem por meio de tecnologias. No entanto, não é considerado como $\mathrm{EaD}$, por essa ser uma modalidade de educação regulamentada pelo Ministério da Educação; possuir a figura do tutor; ser bem mais estruturada e organizada e ter sido desenhada para um público adulto disciplinado e autônomo (GROSSI, 2020).

Outros termos que também têm sido confundidos com 0 ensino remoto, são abordagens pedagógicas que fazem parte das metodologias ativas, tais como o ensino híbrido e a sala de aula invertida. $O$ ensino híbrido combina atividades presenciais e online realizadas dentro ou fora do espaço escolar (BACICH et al. 20I5) e, a sala de aula invertida que tem como princípio a apresentação dos conteúdos das disciplinas aos alunos, por meio de recursos digitais e antes do encontro com o professor (VALENTE, 20I4). 
Usar tecnologias digitais nas aulas remotas durante a pandemia da COVID-19? Sim, mas quais e como usar?

Um aspecto que merece ser elucidado diz respeito ao local onde os alunos estão fazendo suas aulas: em casa e junto com suas famílias. Esse fato fez com que algumas pessoas denominassem erroneamente $\mathrm{o}$ ensino remoto de homeschooling (ensino familiar). $O$ homeschooling tem uma proposta diferente, cujo objetivo é preparar o indivíduo no que se refere à autonomia no seu processo de aprendizado, tornando-o sujeito responsável pelo seu conhecimento, segundo a Associação Nacional de Educação Domiciliar (ANED).

Posto isso, observa-se que a interseção entre essas modalidades de educação, segmentos e abordagens pedagógicas e o ensino remoto, é o uso das TDIC. No caso específico do ensino remoto, essas tecnologias têm duas vertentes: elas são ao mesmo tempo o meio pelo qual as escolas estão levando o ensino aos alunos (via internet) e, também o instrumento que está sendo usado pelos professores para ministrar suas aulas.

\section{As tecnologias digitais e o ensino remoto: algo novo no fazer docente}

Nesse processo de reestruturação da escola, a proposta foi disponibilizar as aulas online com apoio das TDIC. Essas tecnologias podem ser classificadas como apresentado na Figura I. Salienta-se que o Ambiente virtual de Aprendizagem (AVA) é a plataforma de aprendizagem, local onde as aulas online acontecem e são suportados pelas TDIC. Vale ressaltar que existem outras ferramentas e aplicativos que fazem parte do conjunto de TDIC e AVA, aqui foram escolhidos os que a autora desse estudo tem mais familiaridade.

Figura I: Possibilidades de tecnologias digitais para uso no ensino remoto.

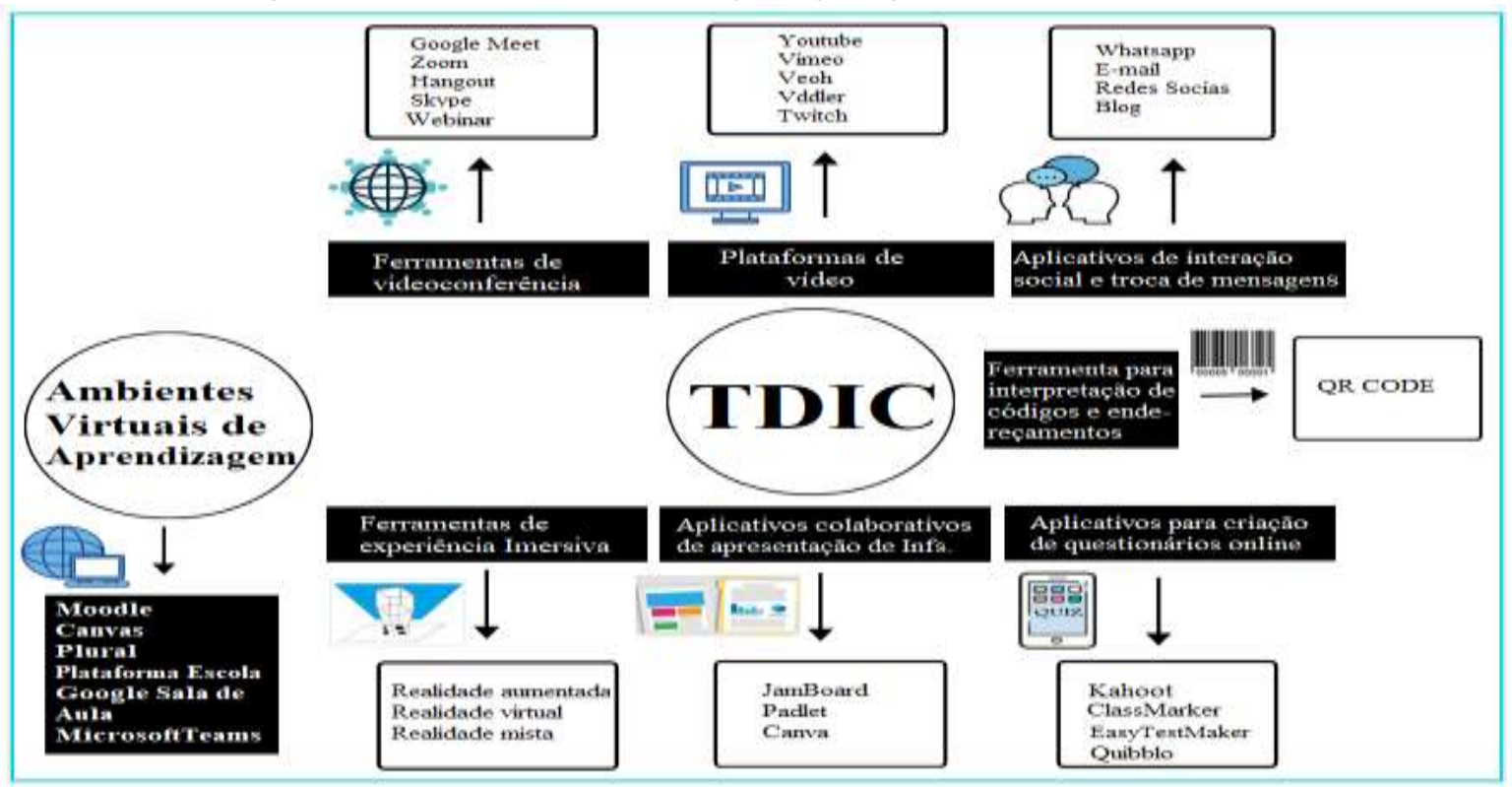

Fonte: Elaborado pela autora, 2020.

Olhar de professor, Ponta Grossa, v. 24, p. I-12, e-15879.059, 2021.

Disponível em <https://revistas2.uepg.br/index.php/olhardeprofessor> 
As TDIC e os AVA estão sendo responsáveis pela reconfiguração do espaço social, no qual a educação faz parte, modificando o fazer docente. Pois, essas tecnologias permitem inúmeras alternativas de estratégias de aprendizagem. Porém, o uso das tecnologias digitais na prática pedagógica exige dos professores apropriação tecnológica, a qual representa um processo de evolução instrucional. Para Sandholtz, Ringstaff e Dwyer (1997) essa evolução compreende cinco etapas: exposição, adoção, adaptação, apropriação e inovação. Mas, devido à suspensão das aulas e, o ensino passar a ser ofertado remotamente, os professores não tiveram o tempo necessário para completar todo o processo. Então, foram selecionadas algumas estratégias pedagógicas que podem ajudar o professor, que ainda não tem apropriação tecnológica, durante suas aulas remotas (Quadro 2).

Quadro 2 - Sugestões de estratégias pedagógicas ativas que podem ser usadas no ensino remoto.

\begin{tabular}{|c|c|c|c|}
\hline $\begin{array}{l}\text { Estratégias } \\
\text { pedagógicas }\end{array}$ & $\begin{array}{c}\text { Tecnologias e } \\
\text { digitais } \\
\text { sugeridas }\end{array}$ & Como usar & Vantagens \\
\hline $\begin{array}{l}\text { Contação de } \\
\text { história } \\
\text { (storytelling) }\end{array}$ & $\begin{array}{l}\text { *Vídeos. } \\
\text { * Ferramentas de } \\
\text { experiências } \\
\text { imersivas } \\
\text { (realidade } \\
\text { aumentada, } \\
\text { realidade virtual } \\
\text { e realidade } \\
\text { mista) } \\
\text { *QR Code. } \\
\text { *Infográficos, } \\
\text { quadros } \\
\text { interativos e } \\
\text { colaborativos } \\
\text { (Jamboard, padlet, } \\
\text { dentre outros). }\end{array}$ & $\begin{array}{l}\text { *O professor usa de animações } \\
\text { com infográficos, textos, cenários } \\
\text { e vídeos para contar uma história } \\
\text { (uma narrativa visual e/ou textual) } \\
\text { para explicar um conteúdo de sua } \\
\text { disciplina. } \\
\text { * Podem ser criados personagens } \\
\text { e a história pode ser produzida } \\
\text { colaborativamente entre } \\
\text { professor e alunos. } \\
\text { * As histórias podem envolver } \\
\text { diferentes disciplinas, permitindo } \\
\text { a participação de vários } \\
\text { professores. }\end{array}$ & $\begin{array}{l}\text { *Oportuniza o uso de } \\
\text { diferentes recursos } \\
\text { audiovisuais, alcançando os } \\
\text { diferentes estilos de } \\
\text { aprendizagem dos alunos } \\
\text { (BACICH et al., 20I5). } \\
\text { *Torna a aula mais criativa e } \\
\text { interessante. } \\
\text { *Provoca as conexões entre } \\
\text { o que o aluno já sabe com } \\
\text { que está apresentado } \\
\text { (colocando em prática a } \\
\text { aprendizagem significativa). } \\
\text { *Possibilita a } \\
\text { interdisciplinaridade. } \\
\text { * Constrói e transmite } \\
\text { valores e conhecimentos } \\
\text { (TAVARES, 20I6). }\end{array}$ \\
\hline $\begin{array}{l}\text { Sala de aula } \\
\text { invertida (flipped } \\
\text { clasroom) }\end{array}$ & $\begin{array}{l}\text { * Vídeo, blogs, } \\
\text { textos, fóruns. } \\
\text { *Whatsapp, e- } \\
\text { mail e Skype } \\
\text { *Ferramentas de } \\
\text { videoconferência, } \\
\text { por exemplo, } \\
\text { Zoom, Google } \\
\text { Meet ou o } \\
\text { Hangout }\end{array}$ & $\begin{array}{l}\text { *O professor disponibiliza nas } \\
\text { plataformas o conteúdo de sua } \\
\text { disciplina e, as instruções de } \\
\text { como deve ser feito o estudo } \\
\text { desses conteúdos. E os alunos, } \\
\text { individualmente ou em grupos, } \\
\text { estudam esse conteúdo sem a } \\
\text { presença do professor (em } \\
\text { horários e locais diferentes das } \\
\text { aulas online). Depois, no horário } \\
\text { da aula o professor, como } \\
\text { mediador do processo, promove } \\
\text { discussões e debates }\end{array}$ & $\begin{array}{l}\text { *Instiga o aluno a estudar em } \\
\text { seu próprio ritmo } \\
\text { (VALENTE, 20I4). } \\
\text { *Permite que o aluno use as } \\
\text { tecnologias que mais tem } \\
\text { afinidade ou disponibilidade. } \\
\text { *Oferece uma educação } \\
\text { diferenciada, adaptada às } \\
\text { particularidades de cada } \\
\text { aluno (BERGMANN; SAMS, } \\
2016 \text { ), oportunizando a } \\
\text { personalização de sua } \\
\text { aprendizagem. }\end{array}$ \\
\hline
\end{tabular}

Olhar de professor, Ponta Grossa, v. 24, p. I-12, e-15879.059, 2021.

Disponível em <https://revistas2.uepg.br/index.php/olhardeprofessor> 
Usar tecnologias digitais nas aulas remotas durante a pandemia da COVID-19? Sim, mas quais e como usar?

\begin{tabular}{|c|c|c|c|}
\hline & & $\begin{array}{l}\text { coletivamente sobre o conteúdo } \\
\text { disponibilizado. Os alunos levam } \\
\text { para o debate suas dúvidas e } \\
\text { considerações sobre o tema } \\
\text { estudado. }\end{array}$ & $\begin{array}{l}\text { *Propicia que o aluno se } \\
\text { torne sujeito da sua } \\
\text { aprendizagem e, não } \\
\text { depósito de conteúdos } \\
\text { (BACICH et al., 20I5). } \\
\text { *Favorece o engajamento do } \\
\text { aluno por meio do } \\
\text { levantamento de questões } \\
\text { sobre o tema proposto. }\end{array}$ \\
\hline Gamificação & $\begin{array}{l}\text { * Ferramentas de } \\
\text { experiências } \\
\text { imersivas, como } \\
\text { a realidade } \\
\text { aumentada, a } \\
\text { realidade virtual } \\
\text { e a realidade } \\
\text { mista. } \\
\text { * Quiz interativo, } \\
\text { que possui } \\
\text { ranking, como, } \\
\text { por exemplo, o } \\
\text { Kahhoot. } \\
\text { *Aplicativos para } \\
\text { troca de } \\
\text { mensagens como } \\
\text { o Whatsapp, } \\
\text { dentre outros. } \\
\text { * Ferramenta de } \\
\text { interpretação de } \\
\text { códigos e } \\
\text { endereçamentos, } \\
\text { como o QR } \\
\text { Code. }\end{array}$ & $\begin{array}{l}\text { * Pode ser trabalhada de forma } \\
\text { online com jogos em sala, a partir } \\
\text { do conteúdo da disciplina. O } \\
\text { professor cria uma história (ou } \\
\text { usa uma pronta) e define com os } \\
\text { alunos os objetivos, as regras, os } \\
\text { desafios e os rankings e medalhas, } \\
\text { ou seja, usas os elementos de um } \\
\text { jogo. Cria cenários (ou usa } \\
\text { software já pronto para tal) com } \\
\text { diferentes desafios a serem } \\
\text { alcançados para que o aluno } \\
\text { durante o caminho percorrido } \\
\text { tenha contato com o conteúdo. É } \\
\text { interessante que os avanços } \\
\text { garantem recompensas, como } \\
\text { mais vidas e acesso à próxima } \\
\text { fase. E os insucessos retiram as } \\
\text { vidas e os pontos conquistados } \\
\text { (MOLINARI, 20I9). Uma } \\
\text { possibilidade é o scape room que } \\
\text { são jogos baseados em resolução } \\
\text { de enigmas e feitos } \\
\text { colaborativamente. Os enigmas } \\
\text { devem ser resolvidos em um } \\
\text { tempo pré-estabelecido pelo } \\
\text { professor. } \\
\text { *Também pode ser usado um quiz } \\
\text { interativo, abordando o tema de } \\
\text { uma aula: o professor cria o } \\
\text { questionário e disponibiliza o } \\
\text { acesso para os alunos por meio } \\
\text { de código, o qual pode ser de } \\
\text { forma colaborativa ou individual } \\
\text { (MONTE et al., 20I7). }\end{array}$ & $\begin{array}{l}\text { *Promove a interação entre } \\
\text { os alunos de uma forma } \\
\text { lúdica e criativa, motivando- } \\
\text { os no processo de } \\
\text { aprendizagem. } \\
\text { *Oferece rápidos feedbacks } \\
\text { dos desempenhos dos alunos } \\
\text { (FRADO, 20I3). } \\
\text { *Facilita para o aluno a } \\
\text { visualização do efeito de suas } \\
\text { ações e aprendizagens, na } \\
\text { medida em que fica mais fácil } \\
\text { compreender a relação das } \\
\text { partes com o todo, como } \\
\text { acontece nos games } \\
\text { (FRADO, 20I3). } \\
\text { *Potencializa o uso de } \\
\text { atividades com recursos } \\
\text { audiovisuais. }\end{array}$ \\
\hline $\begin{array}{l}\text { Criação conjunta } \\
\text { de textos }\end{array}$ & AVA Moodle & $\begin{array}{l}\text { *No link ativar edição (no } \\
\text { Moodle), o professor libera a } \\
\text { atividade Wiki e define um tema } \\
\text { para que os alunos adicionem ou } \\
\text { editem uma coleção de páginas } \\
\text { web. A Wiki pode ser colaborativa } \\
\text { ou individual. Um histórico de } \\
\text { versões de cada página Wiki é } \\
\text { mantido, listando as edições feitas } \\
\text { por cada aluno. O professor vai } \\
\text { mediando e comentando as } \\
\text { postagens. }\end{array}$ & $\begin{array}{l}\text { * Proporciona a produção do } \\
\text { trabalho escolar colaborativo } \\
\text { e, permite a elaboração de } \\
\text { projetos criativos (COLE; } \\
\text { FOSTER, 2007). }\end{array}$ \\
\hline
\end{tabular}

Olhar de professor, Ponta Grossa, v. 24, p. I-12, e-15879.059, 2021.

Disponível em <https://revistas2.uepg.br/index.php/olhardeprofessor> 


\begin{tabular}{|c|c|c|c|}
\hline $\begin{array}{l}\text { Criação conjunta } \\
\text { de dicionário }\end{array}$ & AVA Moodle & $\begin{array}{l}\text { *No link ativar edição (no } \\
\text { Moodle) o professor libera a } \\
\text { atividade Glossário para que os } \\
\text { alunos criem ou atualizem um } \\
\text { dicionário com definições de } \\
\text { termos referentes a um } \\
\text { conteúdo. O professor pode } \\
\text { exportar itens de um glossário } \\
\text { secundário ao glossário principal } \\
\text { da mesma disciplina. É possível } \\
\text { criar automaticamente links em } \\
\text { textos da disciplina que } \\
\text { direcionarão aos itens no } \\
\text { glossário. }\end{array}$ & $\begin{array}{l}\text { * Exige dos alunos um alto } \\
\text { nível de organização, um } \\
\text { esforço de síntese, uma } \\
\text { postura investigativa e } \\
\text { colaborativa, além de espírito } \\
\text { crítico (LEITE, 20I3). }\end{array}$ \\
\hline
\end{tabular}

Fonte: Elaborado pela autora, 2020.

Diante das sugestões apresentados no Quadro 2, observa-se que as tecnologias digitais exigem uma inovação pedagógica e contribuem para a (re)criação dos processos de ensino e aprendizagem utilizando a convergência entre as tecnologias digitais e o ensino tradicional, na tentativa de reprodução de um espaço mais próximo possível da aula presencial, incluindo a comunicação bidirecional entre professor e alunos (ROSA, 20I7).

Dessa forma, é possível perceber que a educação está passando por um momento histórico: a transição do modelo atual que até então era baseado na época da revolução industrial (BERGMANN; SAMS, 2016) para um modelo de educação digital híbrido.

A sugestão final aos professores é que eles façam, juntamente com seus pares e com as escolas, uma reflexão sobre o potencial educativo das tecnologias digitais nas suas práticas docentes, elencando seus limites, suas dificuldades e suas possibilidades. Para então, completarem o processo evolutivo instrucional proposto por Sandholtz, Ringstaff e Dwyer (1997) e assim conseguirem dialogar com as tecnologias digitais.

\section{Considerações finais}

O primeiro ponto esclarecido nesta pesquisa foi que o ensino que vem sendo ofertado durante a pandemia da COVID-19, em caráter emergencial, temporário e mediado pela tecnologia, é o ensino remoto. Esse não é considerado $\mathrm{EaD}$ (que é uma modalidade de educação bem estrutura e organizada para um público mais adulto) e também não é homeschooling (que é uma proposta de ensino doméstico sem a participação de uma instituição de ensino). Portanto, o ensino remoto que vem sendo praticado durante as suspensões das aulas é uma estratégia pedagógica que se assemelha ao ensino híbrido, não sendo considerado 
Usar tecnologias digitais nas aulas remotas durante a pandemia da COVID-19? Sim, mas quais e como usar? uma modalidade de educação. Além disso, destaca-se que não há a intenção governamental de torná-lo um novo sistema educacional.

A pesquisa permitiu responder à questão norteadora que a originou: como as tecnologias digitais podem ser inseridas nas práticas pedagógicas das aulas ofertadas remotamente via internet? A resposta é que elas precisam ser vistas como principais aliadas dos professores, que embora represente um desafio, tem o poder de inovar as antigas práticas, exigindo dos professores apropriação tecnológica.

E o potencial educativo das tecnologias digitais reside no fato de que elas são capazes de transformar o ensino e têm um lugar na construção do conhecimento, exercendo um papel importante no novo contexto educacional, cuja sala de aula passou a ser virtual. Como contribuição, a pesquisa apresentou as principais tecnologias digitais que podem ser usadas nas aulas remotas durante o isolamento social, devido à pandemia da COVID-19, bem como suas aplicações em estratégias pedagógicas, apontando as vantagens para cada uma dessas.

Enfim, o segredo do sucesso do processo de ensino e aprendizagem, seja no ensino presencial ou no ofertado remotamente, não está na escolha das tecnologias digitais de apoio às aulas. O segredo está na alma do professor, fazendo com que a educação continue sendo humana, mesmo quando intermediada por máquinas.

\section{Referências}

ANED. Associação Nacional de Educação Domiciliar. Entenda sobre Educação Domiciliar. Disponível em: <https://www.aned.org.br/sobre-nos/quem-somos-aned>. Acesso em: 20 mai. 2020.

BACICH, L.; TANZI NETO, A.; TREVISANI, F. M. (Org.). Ensino Híbrido: Personalização e Tecnologia na Educação. Porto Alegre, 20I5. 270 p.

BERGMANN, J.; SAMS, A. Sala de aula invertida: uma metodologia ativa de aprendizagem. Tradução Afonso Celso da Cunha Serra.I. ed - Rio de Janeiro LTC, 2016.

BRASIL. Ministério da Educação. Portaria n 345, em 19 de março de 2020. Altera a Portaria MEC $n^{\circ}$ 343, de 17 de março de 2020. 2020. Disponível em: <https://abmes.org.br/arquivos/legislacoes/Portaria-mec-345-2020-03-19.pdf>. Acesso em: 20 mai. 2020.

COSTA, R. Educação remota emergencial x EaD: desafios e oportunidades. 2020. Disponível em: <https://www.linkedin.com/pulse/educa\%25C3\%25A7\%25C3\%25A3o-remotaemergencial-x-ead-desafios-e-renata-costa>. Acesso em: 04 mai. 2020. 
COLE, J.; FOSTER, H. Using Moodle: Teaching with the Popular Open Source Course Management System. Second Edition. O'Reilly Community Press: Printed in the United States of America, November, 2007.

GROSSI, M. G. R. O ensino remoto é uma modalidade de educação? 2020. Disponível em: <https://avacefetmg.org.br/>. Acesso em: 17 mai. 2020.

LEITE, M. T. M. O ambiente virtual de aprendizagem Moodle na prática docente: conteúdos pedagógicos. Laboratório de Educação a Distância - UNIFESP. 2006. Disponível em: <http://www.virtual.unifesp.br/cursos/oficinamoodle/textomoodlevvirtual.pdf>. Acesso em: 05 de jun. 2020.

MARTINS, L. C. B. Implicações da organização da atividade didática com uso de tecnologias digitais na formação de conceitos em uma proposta de Ensino Híbrido. 2016. 317f. Tese (Doutorado em Psicologia) - Programa de Pós-Graduação em Psicologia, Universidade de São Paulo, São Paulo, 2016.

MOLINARI, D. Gamificação na sala de aula: jogar para aprender. 20 I 9. Disponível em: <https://revistaeducacao.com.br/2019/07/0 I/gamificacao-na-sala-de-aula/>. Acesso em: 05 jun. 2020.

MONTE, W. S.; BARRETO, M.; ROCHA, Alexsandra B. Gamification e a web 2.0: planejando processo ensino-aprendizagem. HOLOS, Ano 32, v. 03, p. 90-97, 2017.

MORAN, J. Metodologias ativas e modelos híbridos na educação. In: YAEGASHI, Solange e outros. (Orgs.). Novas Tecnologias Digitais: Reflexões sobre mediação, aprendizagem e desenvolvimento. CRV, p.23-35, 2017, Curitiba. Disponível em: <http://www2.eca.usp.br/moran/wp-content/uploads/2018/03/Metodologias_Ativas.pdf>. Acesso em: 17 mai. 2020.

ROSA, A. A. C. As tecnologias digitais de informação e comunicação (TDIC) e o ensino a distância: reflexões para estudos de currículo. The ESPecialist: Descrição, Ensino e Aprendizagem, v.38, n.2, p. I-23, 2017.

SANDHOLTZ, J. H.; RINGSTAFF, C.; DWYER, D. C. Ensinando com tecnologia: criando salas centradas nos alunos. Porto Alegre: Artes Médicas, 1997.

TAVARES, D. P. O storytelling como estratégia na representação do conhecimento: estudo de caso das hipermídias do projeto e-Tec idiomas. 2016. I60F. Dissertação (Mestrado em Educação e Tecnologia) - Programa de Pós-Graduação do Instituto Federal de Educação, Ciência e Tecnologia Sul-Rio-Grandense, Pelotas, 2016. 
UNESCO. Organização das Nações Unidas para a Educação, Ciência e Cultura. A UNESCO reúne organizações internacionais, sociedade civil e parceiros do setor privado em uma ampla coalizão para garantir a \#AprendizagemNuncaPara. 2020. Disponível em: <https://pt.unesco.org/news/unesco-reune-organizacoes-internacionaissociedade-civil-e-parceiros-do-setor-privado-em-uma>. Acesso em: I4 mai. 2020.

VALENTE, J. A. Blended learninge as mudanças no Ensino Superior: a proposta da sala de aula invertida. Educar em Revista, Curitiba, Edição Especial, n.4, p. 79-97, 2014.

Recebido em: 10 de junho de 2020.

Versão corrigida recebida em: 24 de agosto de 2020.

Aceito em: 24 de agosto de 2020.

Publicado online em: II de junho de 202I. 